\title{
Childhood Poisoning Cases Admitted to Zagazig University Hospitals during the Year 2018: A Retrospective Study
}

\author{
Abeer Ramzy Hussieny Mahmoud \\ Forensic Medicine and Clinical Toxicology Department, Faculty of Medicine, Zagazig University, Zagazig, Egypt \\ Email: lovelylomy_2009@yahoo.com
}

How to cite this paper: Mahmoud, A.R.H. (2019) Childhood Poisoning Cases Admitted to Zagazig University Hospitals during the Year 2018: A Retrospective Study. Occupational Diseases and Environmental Medicine, 7, 115-123.

https://doi.org/10.4236/odem.2019.74009

Received: August 6, 2019

Accepted: August 31, 2019

Published: September 3, 2019

Copyright $\odot 2019$ by author(s) and Scientific Research Publishing Inc. This work is licensed under the Creative Commons Attribution International License (CC BY 4.0).

http://creativecommons.org/licenses/by/4.0/

\begin{abstract}
Background: Childhood poisoning is considered major socioeconomic and public health problem as there are thousands of children admitted to the emergency departments and millions of calls are made to poison control centers every year. Aim of the Work: Determine the prevalence and pattern of childhood poisoning cases admitted to Zagazig University hospitals. Subjects and Methods: This is a retrospective study on children $<18$ years old presented to Zagazig University hospital emergency department. The study was done from the beginning of January 2018 to the end of December 2018 on total of 624 cases with acute poisoning. All required epidemiological and clinical data were collected and analyzed. Results: A total of 624 childhood poisoning cases, more males than females ( $55.3 \%$ versus $44.7 \%$ respectively), and more in age group of 3 - 6 years old $(40.86 \%)$, more in rural than urban communities (65.06\% against $34.94 \%$ respectively). Oral exposure was the most against other routes (84.94\%). Most cases were unintentional (92.8\%). The prevalence of childhood poisoning in descending order was; compound therapeutic medications (32.69\%) followed by pesticides (26.92\%) then corrosives $(17.31 \%)$, while volatile hydrocarbons (benzene or kerosene) accounted for $(15.38 \%)$ and carbon monoxide $(3.85 \%)$ and others $(3.85 \%)$. Overall, minor cases were the commonest (63\%) while only $3.8 \%$ of cases were severe. About $88.94 \%$ of cases were discharged after completed management while death rate was $0.96 \%$. Conclusion: Most childhood poisoning cases were males, accidentally, mainly by oral route and in rural areas, most commonly in age group of $3-6$ years. Most cases were due to therapeutic medications then pesticide exposures. Most of cases were completely cured.
\end{abstract}

\section{Keywords}

Childhood, Poisoning, Zagazig 


\section{Introduction}

It has been reported that the death rate from poisoning in children and adolescents under 20 years old is about 1.8/100,000 worldwide. So, one of the most common emergencies in childhood is toxic emergencies [1] [2] [3].

Childhood poisoning is a complicated condition resulting from interactive relations of the family, the child, the child's environment and the xenobiotic itself making it frequent [4]. In addition to economic and communities' health damage, childhood poisoning cases also result in an enormous emotional and psychological family load [5]. In any community, risk factors recognition and identification are a primary step for poisoning prevention programs. Reduction of morbidity and mortality can be achieved by risk factor modifications [6].

Educational, cultural, economic and social backgrounds directly affect the underlying cause and agent responsible for childhood poisoning [3] [7].

The objective of this study was to determine the prevalence and pattern of childhood poisoning cases admitted to Zagazig University hospitals.

\section{Patients and Methods}

This was a hospital-based retrospective observational study. Inclusion criteria; acute poisoning cases in children ( $<18$ years old) who presented directly to $\mathrm{Za}$ gazig University hospital emergency department or referred from other hospitals in El-Sharqia governorate after getting informed consent from 1 January 2018 to 31 December 2018. Exclusion criteria; cases presented with allergic reactions, food poisoning cases, chronic cases and acutely poisoned patients aged more than 18 years were excluded from this study.

The included cases were revised for their medical records and the acute poisoning cases were diagnosed and defined according to the following criteria; history of poison exposure with the appropriate clinical picture of the suspected poison and their specific investigations.

The following data were acquired from the medical records:

1) Socio-demographic information: sex, age and residence.

The implicated cases of poisoning were subdivided for comparison between age groups; into: infants (less than one year old), toddlers (1: $<3$ years old), preschool age group ( $3:<6$ years old), school age group ( $6:<12$ years old) and adolescents (12: 18 years old) [8].

2) Circumstances of poisoning: route of exposure, mode of exposure (intentional or unintentional), suspected xenobiotic responsible for poisoning.

3) Severity and outcome of the case; we classified the cases using their data in their clinical records (clinical picture and investigations done) according to the poison severity score (PSS) [9] that classified poisoned cases into four grades, None (0): no signs or symptoms of poisoning, Minor (grade 1): mild or spontaneously resolving symptoms, Moderate (grade 2): prolonged or pronounced symptoms, Severe (grade 3): severe or life-threatening symptoms.

We used statistical descriptive methods (frequency and percentage) to analyze 
data.

\section{Results}

The total number of cases during the period of study was (624) cases, Males outnumbered females (55.3\% versus $44.7 \%$ respectively). Patients were divided into 4 groups according to their ages: younger than 1 year, those between 1 and 3 years, those between 3 and 6 years, those between 6 and 12 years, and those between 12 and 18 years. Those from 3 to 6 years represented the highest age group (56.09\%) followed by age $1-3$ years (16.03\%), followed by age groups of 12 - 18 years, less than 1 years $(10.42 \%$ and $8.81 \%$ respectively) and the least was $6-12$ years $(8.65 \%)$.

According to residence, poisoned cases from rural areas represented the majority of cases (65.06\%), opposite to $34.94 \%$ from urban areas.

Regarding the route of poisoning; the majority of cases were through oral route (84.94\%) while other routes (inhalation, skin, I.V, etc.) accounts only for $15.06 \%$. Most of the poisoned cases were unintentional (92.8\%) while only $7.2 \%$ were intentional.

The prevalence of childhood poisoning cases in descending order were due to compound therapeutic medications (32.69\%) followed by pesticides $(26.92 \%)$ then household corrosives (17.31\%) while volatile hydrocarbons (benzene or kerosene) accounted for $15.38 \%$ and carbon monoxide (3.85\%) and others (3.85\%) (Figure 1).

According to the poison severity score (PSS), we arranged the poisoned cases where the highest percent of cases (63\%) were minor followed by moderate (23.1\%), asymptomatic (10.1\%) and lastly the severe cases that accounted only for $3.8 \%$.

About the outcome, there were of $88.94 \%$ of cases discharged after complete management and $0.96 \%$ death rate. The causes of death were due to severe zinc phosphide poisoning in three cases, paint thinner ingestion in two cases and one case of severe henna toxicity. On the other hand, $10.1 \%$ were discharged against medical advice (Table 1).

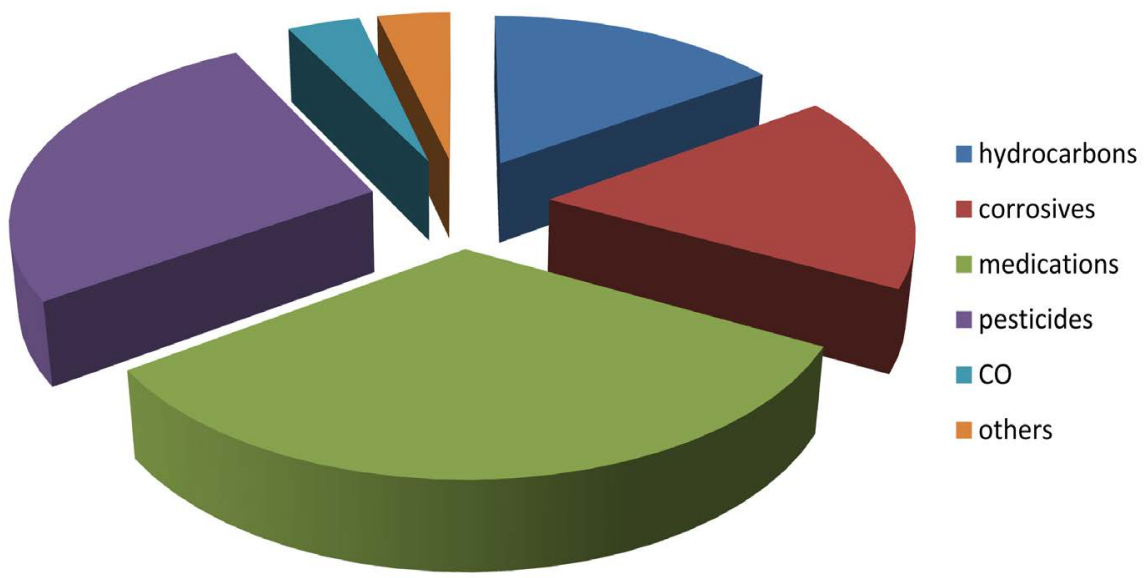

Figure 1. Distribution of major substances involved in childhood poisonings. 
Table 1. Demographic and clinical data of poisoned children during the year 2018 in Zagazig university hospitals (total 624 cases).

\begin{tabular}{|c|c|c|c|}
\hline & Variable & Number & Percent $\%$ \\
\hline \multirow{2}{*}{ Sex } & Male & 345 & $55.3 \%$ \\
\hline & Female & 279 & $44.7 \%$ \\
\hline \multirow{5}{*}{ Age } & $<1$ years & 55 & $8.81 \%$ \\
\hline & $1:<3$ years & 100 & $16.03 \%$ \\
\hline & $3:<6$ years & 350 & $56.09 \%$ \\
\hline & $6:<12$ years & 54 & $8.65 \%$ \\
\hline & $12:<18$ years & 65 & $10.42 \%$ \\
\hline \multirow{2}{*}{ Residence } & Rural & 406 & $65.06 \%$ \\
\hline & Urban & 218 & $34.94 \%$ \\
\hline \multirow{2}{*}{ Route of poisoning } & Oral & 530 & $84.94 \%$ \\
\hline & Other routes & 94 & $15.06 \%$ \\
\hline \multirow{2}{*}{ Mode of exposure } & Unintentional & 579 & 92.8 \\
\hline & Intentional & 45 & 7.2 \\
\hline \multirow{6}{*}{ Involved substances } & hydrocarbons & 96 & $15.38 \%$ \\
\hline & Household corrosives & 108 & $17.31 \%$ \\
\hline & Medications & 204 & $32.69 \%$ \\
\hline & Pesticides & 168 & $26.92 \%$ \\
\hline & $\mathrm{CO}$ & 24 & $3.846 \%$ \\
\hline & Others & 24 & $3.846 \%$ \\
\hline \multirow{4}{*}{ Severity (PSS) } & Asymptomatic (grade 0) & 63 & $10.1 \%$ \\
\hline & Minor (grade 1) & 393 & $63 \%$ \\
\hline & Moderate (grade 2) & 144 & $23.1 \%$ \\
\hline & Severe (grade 3) & 24 & $3.8 \%$ \\
\hline \multirow{3}{*}{ Outcome } & Discharge after completed management & 555 & $88.94 \%$ \\
\hline & Discharge against medical advice & 63 & $10.1 \%$ \\
\hline & Died & 6 & $0.96 \%$ \\
\hline
\end{tabular}

\section{Discussion}

One of the critical causes of emergency unit admissions is acute poisoning. It is considered the third most common emergencies of children resulting in increased economic and social disabilities [10]. For proper preventive measures, it is important to identify the epidemiological pattern of childhood poisoning that we aimed to perform in the current study.

The total number of the admitted cases in the current study was 624 cases 
during the period from $1^{\text {st }}$ of January till the end of December 2018. The higher percentage of cases was males (55.3\%), while females accounted for $44.7 \%$. This result matched other studies of Ahmed et al., 2011 and Akhtar et al., 2006 [11] [12] who explained that boys were more active than girls, which made them highly liable to unintentional exposure to poisons.

According to age, the study showed that those from 3 to 6 years represented the highest age group (56.09\%) followed by the age group (1 - 3 years) which presented $16.03 \%$ of cases, followed by age groups of $12-18$ years and that less than 1 years (10.42\% and $8.81 \%$ respectively) and the least was age group $6-12$ years (8.65\%). Lamireau et al., 2012 [13] and Hahn et al., 2013 [14] studied that children below 6 years old are more liable to poisoning. They supposed that children in this age are inquisitive about their surroundings. They prefer to explore their environment with unawareness of the danger.

Regarding residence, poisoned cases from rural areas represented the majority of cases $(65.06 \%)$, opposite to $34.94 \%$ from urban areas. These results were in agreement with that of Hassan and Siam, 2014 [2] who supposed that there were more available poisons added to more negligence in rural places than in urban once.

Against to these findings, Alazab, 2012 [15] reported higher incidence rate (79.9\%) of childhood poisoning in urban places than in rural ones $(20.1 \%)$. This may be due to difference in the culture of the studied area. In our study, it's known that sharkia governorate is one of the largest agricultural ones in Egypt with more rural areas and peoples.

The majority of cases were through oral route $(84.94 \%)$ while other routes (inhalation, skin, I.V, etc.) accounts only for $15.06 \%$. This may result from easily accessible places of poisons and attractive color or container of the poison for the child. Other studies matched the same result [16] [17]. Most of the studied cases were unintentional (92.8\%) while only $7.2 \%$ were intentional. That agreed Paudyal, 2005 [18] who reported $98.4 \%$ of the study were unintentional poisoning.

Increased accessibility and availability of medications for children in their surroundings might be a principle cause of that added to parenteral negligence. Other factors contributing to childhood poisoning may be inquisitiveness of the child, mother's absence during the day [19]. Addiction or chronic disease or psychiatric illness in a member of the family added to easily accessible medications for children were other factors that increased incidence of childhood poisoning [20] [21].

Therapeutic drugs were the most common cause of poisoning in the present study which constituted about $(32.69 \%)$. This was matched with studies conducted in Turkey [22] and in Iran [23] [24] where poisoning due to medications over-dose was found to be the most common cause of childhood poisoning.

Hassan and Siam, 2014 [2] found that Poisoning with medications was the second most prevalent agent after pesticides in Zagazig university hospitals. Al- 
so, Aglan, 2007 [25] reported that, during the year 2004, chemical and household products represented the highest percentage of acute poisoning $(43.0 \%)$ in children admitted at A in Shams University in Cairo poison control center. These adverse results may be due to change in culture and environmental factors or different duration and time of study.

Poisoning from Pesticide exposure represented also not little percentage of cases $(26.92 \%)$. This matched with many studies who reported a high percentage of pesticide poisoned cases. Henao and Arbelaez 2002 [26] explained in their study that acute pesticide poisoning was common in children living in agricultural communities.

Worldwide; especially in developing countries, the pesticides use has been widely increased either in agriculture or at homes with easy availability and poorly regulated approach. Some pesticides have the affinity to precipitate in the environment. This makes more risk for exposure especially for children [27] [28].

In the present study, cleaning and household corrosive agents accounted for about $17.31 \%$ of the cases of poisoning that agreed to some extent the study of Hyder et al., 2009 [29] who stated that cleaning agents accounted for about 20\% of the cases of poisoning in Egypt, Colombia, Bangladesh and Pakistan. Volatile hydrocarbons (benzene and kerosene) accounted for (15.38\%) which was parallel to other studies done in developing countries [12].

On the other hand, carbon monoxide poisoned cases were about $3.846 \%$ which matched other reports of Mutlu et al., 2010 [30] that in developing countries, there were increased use of cooking fires and poor ventilation at homes.

According to severity, most reported cases (63\%) were minor as most of poisoned cases were of accidental exposure. This matched other Indian studies in 2012 as the highest percentage of cases was grade 1 and 0 [31].

Regarding the outcome, the majority of the studied poisoned cases $(88.94 \%)$ were discharged after completed management while $10.1 \%$ were discharged against medical advice. On the other hand, about $0.96 \%$ died. The cause of death was severe zinc phosphide poisoning in three cases as it is a known rapidly absorbed highly toxic poison, with no appropriate antidotes [32].

These results, more or less, in agreement with Hassan and Siam, 2014 [2] who reported that the majority of cases (86\%) completed their treatment and discharged.

Potential limitations of this retrospective study were some difficulties in data retrieval from unorganized old data files.

\section{Conclusion}

From the previous findings, we concluded that male children are more exposed to poisoning. The age group from 3 to 6 years was the most liable age. Unintentional poisoning was the highest rate of incidence. Oral route was predominant. Therapeutic medications and pesticides were the most accused. 


\section{Conflicts of Interest}

The author declares that they have no conflict of interests.

\section{References}

[1] Cheng, D.R. and Ip, C.C.K. (2012) Unintentional Paediatric Poisoning in Rural Victoria: Incidence and Admission Rates. Australian Journal of Rural Health, 20, 339-343. https://doi.org/10.1111/j.1440-1584.2012.01316.x

[2] Hassan, B.A. and Siam, M.G. (2014) Patterns of Acute Poisoning in Childhood in Zagazig, Egypt: An Epidemiological Study. International Scholarly Research Notices, 2014, Article ID: 245279. https://doi.org/10.1155/2014/245279

[3] Ram, P., Kanchan, T. and Unnikrishnan, B. (2014) Pattern of Acute Poisonings in Children below 15 Years-A Study from Mangalore, South India. Journal of Forensic and Legal Medicine, 25, 26-29. https://doi.org/10.1016/j.jflm.2014.04.001

[4] Azemi, M., Berisha, M., Kolgeci, S. and Bejiqi, R. (2012) Frequency, Etiology and Several Socio-Demographic Characteristics of Acute Poisoning in Children Treated in the Intensive Care Unit. Materia Socio Medica, 24, 76. https://doi.org/10.5455/msm.2012.24.76-80

[5] Oguche, S., Bukbuk, D.N. and Watila, I.M. (2007) Pattern of Hospital Admissions of Children with Poisoning in the Sudano-Sahelian North Eastern Nigeria. Nigerian Journal of Clinical Practice, 10, 111-115.

[6] Soori, H. (2001) Developmental Risk Factors for Unintentional Childhood Poisoning. Saudi Medical Journal, 22, 227-230.

[7] Ahmed, B., Fatmi, Z., Siddiqui, A. and Sheikh, A.L. (2011) Predictors of Unintentional Poisoning among Children under 5 Years of Age in Karachi: A Matched Case Control Study. Pakistan Journal of Public Health, 26, 17-27.

https://doi.org/10.1136/ip.2010.027524

[8] Kail, R.V. (2004) Cognitive Development Includes Global and Domain Specific Processes. Merrill-Palmer Quarterly, 50, 445-455.

https://doi.org/10.1353/mpq.2004.0031

[9] Persson, H.E., Sjoberg, G.K., Haines, J.A. and Pronczuk de Garbino, J. (1998) Poisoning Severity Score. Grading of Acute Poisoning. Journal of Toxicology: Clinical Toxicology, 36, 205-213. https://doi.org/10.3109/15563659809028940

[10] Steele, P. and Spyker, D.A. (1985) Poisonings. Pediatric Clinics of North America, 32, 77-85. https://doi.org/10.1016/S0031-3955(16)34757-5

[11] Ahmed, B., Fatmi, Z. and Siddiqui, A.R. (2011) Population Attributable Risk of Unintentional Childhood Poisoning in Karachi Pakistan. PLoS ONE, 6, e26881. https://doi.org/10.1371/journal.pone.0026881

[12] Akhtar, S., Rani, G. and Al-Anezi, F. (2006) Risk Factors in Acute Poisoning in Children: A Retrospective Study. Kuwait Medical Journal, 38, 33-36.

[13] Lamireau, T., Llanas, B., Kennedy, A., Fayon, M., Penouil, F., Favarell-Garrigues, J. and Demarquez, J.L. (2002) Epidemiology of Poisoning in Children: A 7-Year Survey in a Paediatric Emergency Care Unit. European Journal of Emergency Medicine, 9, 9-14. https://doi.org/10.1097/00063110-200203000-00004

[14] Hahn, R.C., Labegalini, M.P. and Oliveira, M.L. (2013) Features of Acute Poisoning in Children: A Study in Center Toxicological. Brazilian Journal of Surgery and Clinical Research, 4, 18-22.

[15] Alazab, R.M. (2012) Determinants of Acute Poisoning among Children (1-60) 
Months Old at a Poisoning Unit of a University Hospital, Egypt, Are Employed Mothers a Risk Factor? Retrospective Cohort Study. Journal of American Science, 8, 9.

[16] Goksu, S., Yildirim, C., Kocoglu, H., Tutak, A. and Oner, U. (2002) Characteristics of Acute Adult Poisoning in Gaziantep, Turkey. Journal of Toxicology: Clinical Toxicology, 40, 833-837. https://doi.org/10.1081/CLT-120016953

[17] Moazzam, M., Al-Saigul, A., Naguib, M. and Al-Alfi, M. (2009) Pattern of Acute Poisoning in Al-Qassim Region: A Surveillance Report from Saudi Arabia, 1999-2003. Eastern Mediterranean Health Journal, 15, 1005-1010. https://doi.org/10.26719/2009.15.4.1005

[18] Paudyal, B.P. (2005) Poisoning: Pattern and Profile of Admitted Cases in a Hospital in Central Nepal. Journal of Nepal Medical Association, 44, 92-96.

[19] Baaker, R.H. (2010) Risk Factors for Childhood Poisoning: A Case-Control Study in Baghdad. Mustansiriya Medical Journal, 9, 6-12.

[20] KhosraviShadmani, F., Rajabi, A. and Gholami, A. (2016) Compare the Estimated Odds Ratios from Logistic Regression and Conditional Logistic Regression in the Case-Control Study Determination Risk Factors for Unintentional Childhood Poisoning of Children in Tehran. Zanco Journal of Medical Sciences, 6, 10-21.

[21] Mansori, K., Soori, H., Farnaghi, F., Khodakarim, S., MansouriHanis, S. and Khodadost, M. (2016) A Case-Control Study on Risk Factors for Unintentional Childhood Poisoning in Tehran. Medical Journal of the Islamic Republic of Iran, 30, 355.

[22] Andiran, N. and Sarikayalar, F. (2004) Pattern of Acute Poisonings in Childhood in Ankara: What Has Changed in Twenty Years? The Turkish Journal of Pediatrics, 46, 147-152.

[23] Ansari-Moghaddam, A., Martiniuk, A.L., Mohammadi, M., Rad, M., Sargazi, F., Sheykhzadeh, K., Jelodarzadeh, S. and Karimzadeh, F. (2012) The Pattern of Injury and Poisoning in South East Iran. BMC International Health and Human Rights, 12, 17. https://doi.org/10.1186/1472-698X-12-17

[24] Disfani, H.F., Kamandi, M., Mousavi, S.M., Sadrzadeh, S.M., Farzaneh, R., Doolabi, N. and Rahmani, K. (2019) Risk Factors Contributing to the Incidence and Mortality of Acute Childhood Poisoning in Emergency Department Patients in Iran: A Hospital-Based Case-Control Study. Epidemiology and Health, 41, e2019016. https://doi.org/10.4178/epih.e2019016

[25] Aglan, M.A. (2007) Epidemiologic Retrospective Study of Acute Poisoning in Children Attending Poison Control Center, Ain Shams University in the Year 2004 Speculation of Renal Affection. Thesis: MSc Pediatrics.

[26] Henao, S. and Arbelaez, M. (2002) Epidemiologic Situation of Acute Pesticide Poisoning in Central America, 1992-2000. Epidemiological Bulletin, 23, 5-9.

[27] Eddleston, M., Karalliedde, L., Buckley, N., Fernando, R., Hutchinson, G. and Isbister, G. (2002) Pesticide Poisoning in the Developing World-A Minimum Pesticides List. The Lancet, 360, 1163-1167. https://doi.org/10.1016/S0140-6736(02)11204-9

[28] Soltaninejad, K. and Shadnia, S. (2014) History of the Use and Epidemiology of Organophosphorus Poisoning. In: Basic and Clinical Toxicology of Organophosphorus Compounds, Springer, Berlin, 25-43. https://doi.org/10.1007/978-1-4471-5625-3 2

[29] Hyder, A., Sugerman, D. and Puvanachandra, P. (2000) Childhood Unintentional Injury Surveillance: A Multi-Site Pilot Study. Johns Hopkins University and World 
Health Organization, Baltimore.

[30] Mutlu, M., Cansu, A., Karakas, T., Kalyoncu, M. and Erduran, E. (2010) Pattern of Pediatric Poisoning in the East Karadeniz Region between 2002 and 2006: Increased Suicide Poisoning. Human \& Experimental Toxicology, 29, 131-136. https://doi.org/10.1177/0960327109357141

[31] Jose, A., Sivanandam, S. and Matthai, J. (2012) Poisoning in Children from an Educationally and Economically Advanced Urban Area of South India. Asian Journal of Epidemiology, 5, 123-129. https://doi.org/10.3923/aje.2012.123.129

[32] Kandeel, F.S. and EL-Farouny, R.H. (2017) Study of Acute Poisoning Cases in Children Admitted to Menoufia Poison Control Center (MPCC) during the Year 2016: A Prospective Study. Ain Shams Journal of Forensic Medicine and Clinical Toxicology, 29, 89-99. https://doi.org/10.21608/ajfm.2017.18213 